Part of Journal of Research of the National Bureau of Standards, Volume 35, August 1945

\title{
MASS SPECTROMETRIC ANALYSES OF HYDROCARBON AND GAS MIXTURES ${ }^{1}$
}

\author{
By A. Keith Brewer and Vernon H. Dibeler
}

\section{ABSTRACT}

The basic principles underlying mass spectrometric analysis of hydrocarbon and gas mixtures are outlined. The method of calculating the composition from the mass-abundance records is described. Analyses of a number of hydrocarbon and other gas mixtures are shown. Whenever possible, comparisons with different methods of analyses are given. The reproducibility and the accuracy obtainable in mass spectrometric analyses are described.

\section{CONTENTS}

I. Page

I. Introduction

II. Description of the mass spectrometer

III. Mass spectra of hydrocarbon molecules_.

IV. Method of calculation

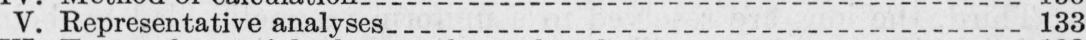

VI. Types of materials that can be analyzed.

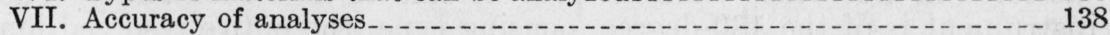

\section{INTRODUCTION}

The basic principles involved in the mass spectrometer were worked out as early as 1910 by Sir J. J. Thomson. The first mass spectrographs utilizing these principles, much as in the present-day instrument, were built by Aston and by Dempster about 1920. In spite of this early conception, it is only within the last 2 years that the mass spectrometer has been developed to the point where it is capable of making precise analyses of gas and hydrocarbon mixtures.

This new development has been made possible, not from changes in principle or basic design, but from the discovery that hydrocarbon molecules upon bombardment at low pressures $\left(10^{-5}\right.$ to $\left.10^{-6} \mathrm{~mm}\right)$ by electrons having 50 or more volts of energy are dissociated into all possible disintegration fragments. ${ }^{2}$ The ratios in which the fragments occur are the same over a wide pressure range for each molecular species but are never the same for different species. The development of sensitive electronic pick-ups and automatic-recording mechanisms has not only contributed to the ease of operation but has made possible a speed and precision that could not be attained by manual controls.

1 This work was financed in part from funds made available by the Rubber Reserve Co.

H. Hoover, Jr. and H. W. Washburn, Calif. Oil World Petroleum Ind., (Nov. 1941); H. W. Washburn, H. F. Wiley, and S. M. Rock, Ind. Eng. Chem. Anal. Ed. 15, 541 (1943); H. W. Washburn, H. F. Wiley, S. M. Rock, and C. E. Berry, Ind. Eng. Chem. Anal. Ed. 17, 74 (1945). 
This paper describes briefly the method by which chemical composition can be determined from mass spectrometric records, the types of mixtures that are being analyzed, and the reproducibility that is being realized. Representative analyses made in the mass spectrometer laboratory at the National Bureau of Standards by the use of a mass spectrometer manufactured by the Consolidated Engineering Corporation are cited to illustrate the applicability of the instrument.

\section{DESCRIPTION OF THE MASS SPECTROMETER}

In the mass spectrometer, molecular masses are separated by virtue of differences in their momenta when all have been given an identical kinetic energy in a given direction. Four steps are involved in the separation.

First, the molecules are given a positive charge. This is accomplished in the instrument by bombardment with a stream of 50 -volt electrons, the electron current being about 5 microamperes. The gas pressure in the ionizing chamber is of the order of $10^{-5}$ millimeter. The filament is placed outside the ionization chamber, where the gas pressure, as measured on an ionization gage, ranges from $10^{-7}$ to $10^{-6}$ millimeter. This insures long filament life and prevents products of molecules cracked on the hot filament from reentering the ionizing chamber.

Second, the ions are given an identical kinetic energy along a given path by a potential difference between two accelerating slits. In the instrument this potential can be manually or automatically varied from 4,000 to 200 volts. The kinetic energy of the ions is given by $1 / 2 m v^{2}=e E$, where $m$ is the ion mass, $v$ the velocity, $e$ the charge on the ion, and $E$ the accelerating potential.

Third, the ions are resolved in a uniform magnetic filed by being deflected in arcs whose radii are proportional to their momenta. The instrument is of the 180-degree focusing type, the entire resolved ion path being within the uniform magnetic field of a large electro magnet.

The centripetal force deflecting the ions is balanced by centrifugal force, as expressed by $H e v=m v^{2} / r$, where $H$ is magnetic field strength and $r$ is the radius of deflection. Dividing both sides by $v$ and rearranging, the above expression gives $m v=H e r$; this shows the radius to be proportional to the momentum. Substituting the energy value for $v$ in the momentum equation, the basic expression for the principle of the mass spectrometer is obtained as $(m / e)=\left(H^{2} r^{2}\right) / 2 E$. Expressing all values in practical units this equation becomes

$$
H r=\left[\frac{2 \times 1.66 \times 10^{-24} \times m V}{4.803 \times 10^{-10} \times 300}\right]^{1 / 2} \times 3 \times 10^{10}=144.00 \sqrt{m} \sqrt{V,}
$$

where $H$ is in gauss, $V$ in volts, $r$ in centimeters, and $m$ in units of hydrogen atoms.

Fourth, the resolved ion beams are collected and recorded. In the instrument the focusing radius, $r$, is fixed at 12.7 centimeters. The various masses are made to pass over the collector slit by varying $V$ while $H$ is kept constant. This is accomplished by permitting the charge on the ion-accelerating slit to leak to ground through a high resistance. As the potential decreases a progression of masses from light to heavy is brought to focus on the collector slit. The arrangement chosen has the advantage of providing a nearly linear record as 
the radius of the ion path varies as the square root of the mass, whereas the rate of potential leak is inversely proportional to the voltage.

The resolved ion masses are collected and the ion current is amplified by a direct-current feed-back amplifier. The output is fed through four galvanometers in series. Shunts are provided to reduce the sensitivity of the second, third, and fourth galvanometers to onethird, one-tenth, and one-thirtieth that of the first. This gives the 8 -inch-wide recording paper an effective width of 240 inches. The deflections of the four galvanometers as well as the scale divisions are photographed simultaneously on the moving record.

A mass marker is provided to make possible the easy identification of the various mass numbers. The marker consists of a relay that trips at definite intervals to throw a spot of light on the moving record when the acceleration potential passes fixed multiples of a chosen reference voltage.

\section{MASS SPECTRA OF HYDROCARBON MOLECULES}

The ionization potentials of hydrocarbon molecules range from about 9 to 14 volts. The 50 -volt ionizing electrons possess enough energy not only to ionize the molecules but also to dissociate them into all possible fragments. As sufficient molecules are ionized for the probability laws to hold, the fragments of each molecular species always occur in the same abundance ratio.

In table 1 are given the cracking patterns for some of the $\mathrm{C}_{4}$ hydrocarbons.

TABLE 1.-Mass spectrometer calibration patterns

\begin{tabular}{|c|c|c|c|c|c|c|c|c|c|}
\hline$m / e$ & $n$-Butane & Isobutane & Butene-1 & $\begin{array}{c}\text { cis-Bu- } \\
\text { tene-2 }\end{array}$ & $\begin{array}{c}\operatorname{trans}-\mathrm{Bu}- \\
\operatorname{tene-2}\end{array}$ & Isobutene & $\begin{array}{l}\text { 1,2-Bu- } \\
\text { tadiene }\end{array}$ & $\begin{array}{l}\text { 1,3-Bu- } \\
\text { tadiene }\end{array}$ & $\begin{array}{c}\text { Ethyl } \\
\text { acetylene }\end{array}$ \\
\hline $31-$. & $\begin{array}{r}\text { Trace } \\
1.61 \\
46.95 \\
283.03 \\
240.85 \\
297.76 \\
6.65\end{array}$ & $\begin{array}{r}0 \\
3.63 \\
72.73 \\
959.60 \\
106.46 \\
215.15 \\
5.45\end{array}$ & $\begin{array}{r}0.21 \\
2.07 \\
23.94 \\
73.05 \\
64.54 \\
27.34 \\
1.91 \\
.04\end{array}$ & $\begin{array}{r}0.12 \\
1.24 \\
16.77 \\
50.78 \\
47.58 \\
22.33 \\
1.31 \\
.04\end{array}$ & $\begin{array}{r}0.11 \\
1.24 \\
16.43 \\
51.59 \\
49.34 \\
28.56 \\
1.23 \\
.04\end{array}$ & $\begin{array}{r}\text { Trace } \\
0.60 \\
8.57 \\
36.05 \\
37.23 \\
18.16 \\
1.24\end{array}$ & $\begin{array}{r}0.32 \\
2.42 \\
14.31 \\
40.10 \\
25.46 \\
.72 \\
.03\end{array}$ & $\begin{array}{r}0.44 \\
3.29 \\
24.70 \\
63.70 \\
39.50 \\
.88\end{array}$ & $\begin{array}{r}0.45 \\
2.59 \\
12.51 \\
36.77 \\
31.24 \\
1.23\end{array}$ \\
\hline $\begin{array}{l}42 \\
43 \\
44 \\
45\end{array}$ & $\begin{array}{r}.25 \\
6.71 \\
14.63 \\
112.20 \\
15.75 \\
205.28 \\
92.53 \\
734.76 \\
24.14 \\
.30\end{array}$ & $\begin{array}{r}1.21 \\
35.76 \\
86.76 \\
658.59 \\
99.80 \\
1444 \\
1208 \\
3666 \\
118.79 \\
1.41\end{array}$ & $\begin{array}{r}.44 \\
6.81 \\
11.88 \\
88.65 \\
17.18 \\
228.19 \\
7.93 \\
.06\end{array}$ & $\begin{array}{r}.22 \\
3.71 \\
6.86 \\
59.69 \\
11.31 \\
162.21 \\
5.32 \\
.12\end{array}$ & $\begin{array}{r}.20 \\
3.64 \\
6.54 \\
58.99 \\
11.24 \\
166.01 \\
5.47 \\
.07\end{array}$ & $\begin{array}{r}.32 \\
5.31 \\
11.38 \\
84.87 \\
20.78 \\
187.23 \\
6.67 \\
.07\end{array}$ & $\begin{array}{r}.74 \\
5.08 \\
7.39 \\
39.15 \\
1.34\end{array}$ & $\begin{array}{r}.90 \\
5.85 \\
7.85 \\
95.25 \\
3.29 \\
.13\end{array}$ & $\begin{array}{r}1.01 \\
7.99 \\
14.78 \\
77.26 \\
2.58 \\
.03 \\
\\
\end{array}$ \\
\hline $\begin{array}{l}48 \\
49 \\
50 \\
51 \\
52 \\
53 \\
54 \\
55 \\
56 \\
57 \\
58 \\
59 \\
60 \\
\end{array}$ & $\begin{array}{r}.15 \\
1.78 \\
7.62 \\
7.52 \\
2.08 \\
6.66 \\
1.98 \\
7.42 \\
6.20 \\
19.21 \\
100.00 \\
4.35 \\
.07\end{array}$ & $\begin{array}{r}\text { Trace } \\
4.04 \\
22.22 \\
23.03 \\
5.45 \\
20.00 \\
3.23 \\
16.57 \\
13.94 \\
110.30 \\
100.00 \\
4.35 \\
.07\end{array}$ & $\begin{array}{r}.44 \\
2.89 \\
10.59 \\
9.84 \\
3.35 \\
12.84 \\
6.63 \\
40.69 \\
100.00 \\
4.31 \\
.07\end{array}$ & $\begin{array}{r}.29 \\
2.21 \\
9.16 \\
8.98 \\
3.07 \\
12.59 \\
6.72 \\
37.31 \\
100.00 \\
4.31 \\
.07\end{array}$ & $\begin{array}{r}\text { Trace } \\
2.25 \\
9.44 \\
9.30 \\
3.14 \\
13.65 \\
6.29 \\
38.76 \\
100.00 \\
4.31 \\
.07\end{array}$ & $\begin{array}{r}.22 \\
1.82 \\
8.33 \\
7.91 \\
2.22 \\
9.49 \\
4.52 \\
31.28 \\
100.00 \\
4.31 \\
.07\end{array}$ & $\begin{array}{r}1.12 \\
6.24 \\
21.56 \\
19.82 \\
10.60 \\
37.91 \\
100.00 \\
4.30 \\
.07\end{array}$ & $\begin{array}{r}1.22 \\
6.99 \\
23.31 \\
21.21 \\
10.77 \\
55.52 \\
100.00 \\
4.30 \\
.07\end{array}$ & $\begin{array}{r}1.13 \\
6.49 \\
20.68 \\
18.30 \\
7.91 \\
41.67 \\
100.00 \\
4.30 \\
.07 \\
\end{array}$ \\
\hline \multicolumn{10}{|c|}{ SENSITIVITY } \\
\hline & 3. 86 & 0.89 & 11.15 & 12.77 & 12.97 & 14.01 & 19.11 & 16. 76 & 19.50 \\
\hline
\end{tabular}


In preparing table 1 the abundance of the base mass was assigned an arbitrary value of 100 ; and the abundance of all other masses weighted accordingly. The base mass is that of the normal molecule composed of $\mathrm{C}^{12}$ and $\mathrm{H}$ atoms. The only heavier peaks observed are those due to the heavy isotopes, $\mathrm{C}^{13}$ and $\mathrm{D}$. No association between molecules is detected at the pressure existing in the analyzing chamber.

The sensitivity for each compound is given at the bottom of the table. Sensitivity is defined as the number of divisions of base peak per micron of gas pressure. As the peaks are proportional to the pressure over the range in which the instrument is operated, the sensitivity is independent of the sample pressure or of the partial pressure of any constituent present.

The isotopic contribution to successive peaks is shown in table 2.

TABLE 2.-Isotope correction factors

\begin{tabular}{|c|c|c|c|}
\hline Positive ion & $m / e$ & $(m / e)+1$ & $(m / e)+2$ \\
\hline $\begin{array}{l}\mathrm{C} \\
\mathrm{CH} \\
\mathrm{CH}_{2} \mathrm{CH}_{3} \\
\mathrm{CH}_{4}\end{array}$ & $\begin{array}{l}12 \\
13 \\
14 \\
15 \\
16\end{array}$ & \begin{tabular}{r|} 
Percent \\
1.051 \\
1.066 \\
1.081 \\
1.096 \\
1.111
\end{tabular} & $\begin{array}{l}\text { Percent } \\
0 \\
1.6 \times 10^{-4} \\
3.2 \times 10^{-4} \\
4.8 \times 10^{-4} \\
6.4 \times 10^{-1}\end{array}$ \\
\hline $\begin{array}{l}\mathrm{C}_{2} \\
\mathrm{C}_{2} \mathrm{H}_{2} \\
\mathrm{C}_{2} \mathrm{H}_{2} \\
\mathrm{C}_{2} \mathrm{H}_{3} \\
\mathrm{C}_{2} \mathrm{H}_{4} \\
\mathrm{C}_{2} \mathrm{H}_{5}\end{array} \mathrm{C}_{2} \mathrm{H}_{6-2}$ & $\begin{array}{l}24 \\
25 \\
26 \\
27 \\
28 \\
29 \\
30\end{array}$ & $\begin{array}{l}\text { 2. } 102 \\
\text { 2. } 117 \\
\text { 2. } 142 \\
\text { 2. } 162 \\
\text { 2. } 177 \\
\text { 2. } 192\end{array}$ & $\begin{array}{l}0.011 \\
.011 \\
.012 \\
.012 \\
.012 \\
.013 \\
.013\end{array}$ \\
\hline 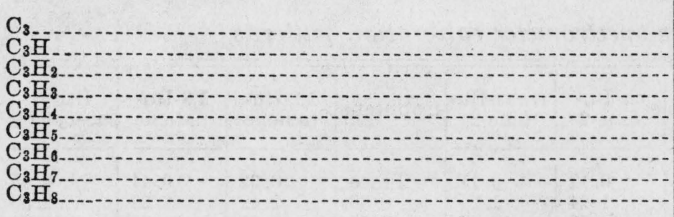 & $\begin{array}{l}36 \\
37 \\
38 \\
39 \\
40 \\
41 \\
42 \\
43 \\
44\end{array}$ & $\begin{array}{l}\text { 3. } 153 \\
\text { 3. } 168 \\
\text { 3. } 183 \\
\text { 3. } 198 \\
\text { 3. } 213 \\
\text { 3. } 228 \\
\text { 3. } 243 \\
\text { 3. } 258 \\
\text { 3. } 273\end{array}$ & $\begin{array}{l}.033 \\
.034 \\
.034 \\
.035 \\
.035 \\
.036 \\
.036 \\
.036 \\
.037\end{array}$ \\
\hline 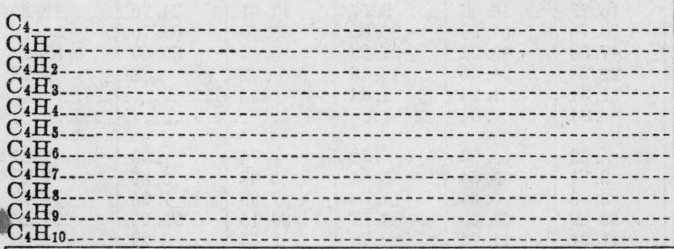 & $\begin{array}{l}48 \\
49 \\
50 \\
51 \\
52 \\
53 \\
54 \\
55 \\
56 \\
57 \\
58 \\
\end{array}$ & $\begin{array}{l}\text { 4. } 204 \\
\text { 4. } 219 \\
\text { 4. } 234 \\
\text { 4. } 249 \\
\text { 4. } 264 \\
\text { 4. } 279 \\
\text { 4. } 294 \\
\text { 4. } 309 \\
\text { 4. } 324 \\
\text { 4. } 339 \\
\text { 4. } 354\end{array}$ & $\begin{array}{l}.066 \\
.067 \\
.068 \\
.068 \\
.069 \\
.069 \\
.070 \\
.071 \\
.071 \\
.072 \\
.073 \\
\end{array}$ \\
\hline
\end{tabular}

The $\mathrm{C}^{13}$ and D contributions for the ions given in column 1 (table 2 ) to the peaks 1 and 2 mass units higher $(m / e+1$ and $m / e+2)$ are computed on the basis of the observed abundance of $\mathrm{C}^{13}$ as 1.051 percent and $\mathrm{D}$ as 0.02 percent.

The masses given in Table 1 are due to singly charged ions. In addition to these, peaks are observed for doubly charged ions, for ghosts, and for "labile" groups, principally hydrogen. In the case of $n$-butane, for instance, the singly charged ions constitute 99.69 percent of the total. The percentage of doubly charged ions is higher for unsaturated hydrocarbons and for diatomic molecules.

Only singly charged ions are used in computing the composition from a mass record. The presence of other ion groups introduces no complication as they occur in proportion to the pressure and are easily distinguished. They are in fact often a help in characterizing the parent molecule.

A mass record for a typical gas mixture"is shown in figure 1. 


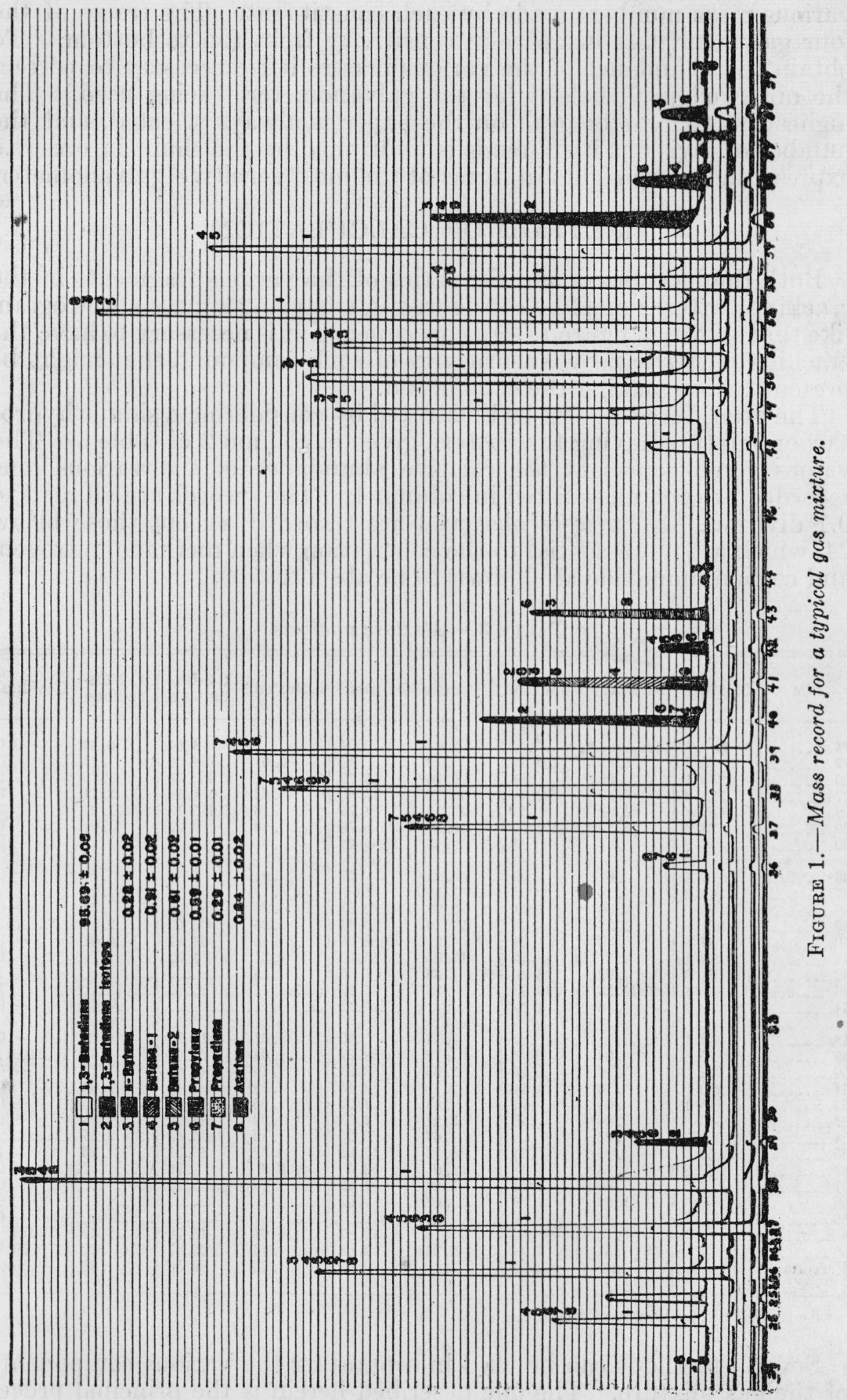


The record has been illuminated to show the contributions to the various mass numbers made by each constituent. The traces of the four galvanometers decrease in sensitivity from top to bottom. To obtain the abundance of the various masses it is necessary to correct the observed peak height for the galvanometer tracing used. The highest galvanometer peak on the paper is always selected, and the number of divisions it subtends is multiplied by the shunt in order to express the peak heights in terms of the most sensitive galvanometer.

\section{METHOD OF CALCULATION}

Both the base peaks and the ratios of the various fragments in the cracking patterns must be considered in analyzing a mass spectrogram like that shown in figure 1. In consequence, it is necessary to have the cracking pattern and the sensitivity of each compound that might be present before making the calculation.

The procedure can best be illustrated by considering a simple hydrocarbon mixture having the pattern given in column 2 of table 3 . The values given represent the relative abundance of the various ions recorded at each mass listed in column 1 . The records are all read to 0.1 division. All masses observed are recorded, except those below 24 , which are not essential to the calculation when methane, nitrogen, and carbon monoxide are known to be absent.

TABLE 3.-Mixture analysis

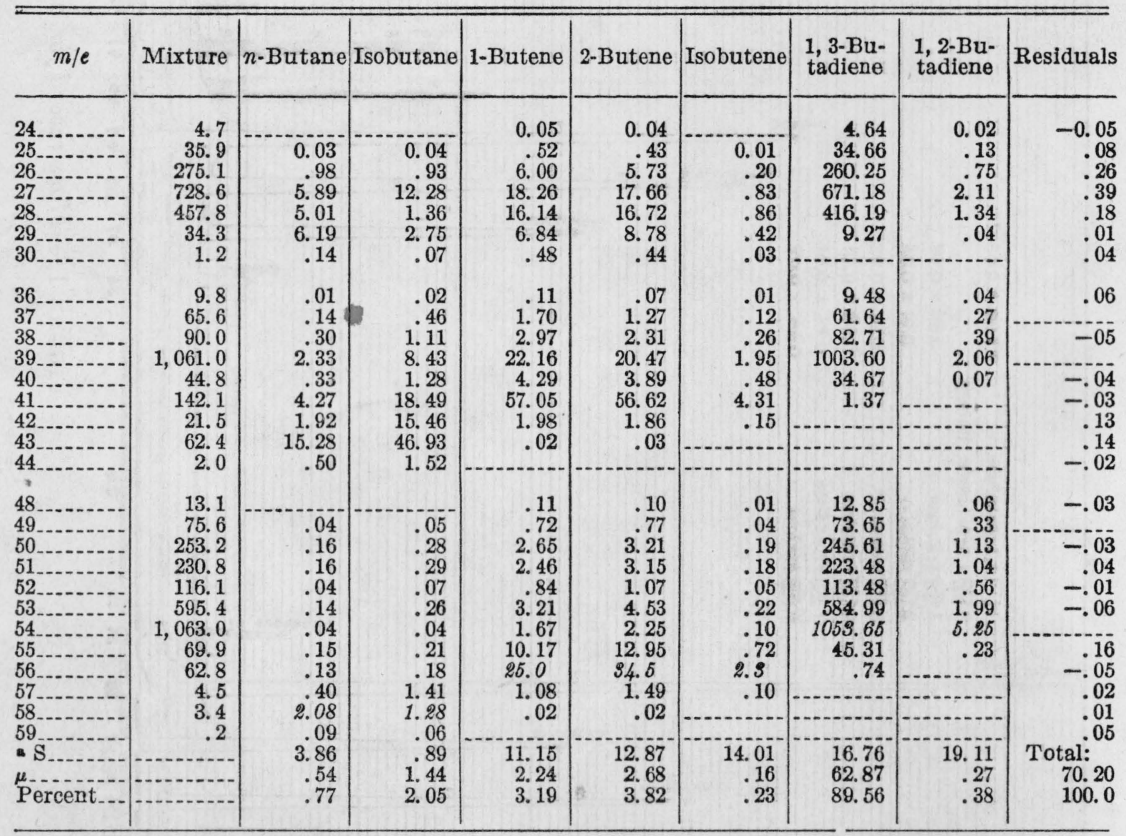

a $\mathrm{S}=$ sensitivity: $\mu=$ mieron of pressure.

Several methods can be used in separating the various components of the gas mixture. The one described herein is the principal procedure used at the National Bureau of Standards. It consists in re- 
moving mathematically the contribution of the various constituents from each mass number. When possible each compound is subtracted individually starting with the highest masses.

A survey of the pattern in column 2 shows clearly that no hydrocarbons are present heavier than butanes of base mass 58 ; the 59 peak can be accounted for fully by the heavy isotope contribution from 58 . The first problem is, therefore, to determine if 58 is due to $n$-butane, to isobutane, or to both. Table 1 shows that $n$ - and isobutanes make very different contributions to the 43 peak, As the 44 peak is the correct size for the isotope contribution from 43 , propane and carbon dioxide are shown to be absent. (In consequence, the only contributors to 58 and 43 , other than butanes, are the second isotopes from 56 and 41 ; these contributions are 0.05 and 0.04 division, respectively.

The relative contribution of $n$ - and isobutanes to the 58 and 43 peaks are expressed by the simple linear equations as

43 peak $=7.3476 n$-butane +36.6667 isobutane $=62.35$ divisions

58 peak $=1.00 n$-butane +1.00 isobutane $\quad=3.36$ divisions.

These can be solved by determinants as follows:

$$
n \text {-Butane }=\left|\begin{array}{cr}
62.35 & 36.67 \\
3.36 & 1.00 \\
7.347 & 36.67 \\
1.00 & 1.00
\end{array}\right|=\frac{-60.85}{-29.3191}=2.08 \text { divisions. }
$$

Similarly, isobutane $=1.28$ divisions. These values appear in columns 3 and 4 at mass 58 . When the two base peaks are multiplied by their respective patterns the contribution of the two butanes to all the masses is obtained and can be subtracted out.

The second step is to remove the butanes shown to be present by the large 56 peak. For sake of simplicity 2-butene will be considered as an equimolar mixture of cis- and trans-isomers. The procedure is the same as that followed for the butanes, but three equations are needed as three butenes are possible. Table 1 shows that with reference to the base peak, the peaks at 55 and 41 are markedly different for the butenes. The only possible remaining compounds tha can contribute to the 55 and 56 peaks are the isotopes from 1, 3-butadiene and ethyl acetylene. Possible remaining contributors to 41 are propenes and the isotope from methyl acetylene.

The approximate nonbutene contributor to the three peaks is first determined; this is later corrected to fit the equations. Propene, having a base peak of 42 , can be determined quite accurately on the first approximation. The butene contribution to 42 is small and does not differ greatly for the three butenes. Taking an average contribution for the butenes, the size of the 42 peak can be calculated from"the 56 peak. In the present case the entire 42 peak can be accounted Ifor by butenes, hence only a trace of propene ${ }^{*}$ can be present. The fact that the 39 peak is almost as large as 54 indicates a large" concentration of 1,3-butadiene and a negligible concentration of "ethyl acetylene. The isotope contributions to the 41,55 , and 56 peaks can now be computed from table 1 ; the values are $1.37,45.71$ and 0.74 divisions, respectively. 
The butenes are now separated by the following linear equations:

41 peak $=2.2819 \mathrm{~B}_{1}+1.6411 \mathrm{~B}_{2}+1.8723 \mathrm{~B}_{1}=117.86$ divisions.

55 peak $=0.4069 \mathrm{~B}_{1}+0.3754 \mathrm{~B}_{2}+0.3128 \mathrm{~B}_{1}=23.83$ divisions.

56 peak $=1.00 \mathrm{~B}_{1}+1.00 \mathrm{~B}_{2}+1.00 \mathrm{~B}_{1}=61.75$ divisions.

Solving by determinants, Butene-1=

$\left|\begin{array}{lll}117.86 & 1.6411 & 1.8723 \\ 23.83 & 0.3754 & 0.3128 \\ 61.75 & 1.00 & 1.00 \\ \hline 2.2819 & 1.6411 & 1.8723 \\ 0.4069 & 0.3754 & 0.3128 \\ 1.00 & 1.00 & 1.00\end{array}\right|=\frac{1.18}{0.0472}=25.0$ divisions.

Similarly, butene- $2=34.5$ division and isobutene $=2.3$ divisions .

The above values for the butenes appear in columns 5,6 , and 7 at mass 56. The contribution of each butene can now be computed and subtracted. The remaining divisions are due to the butadienes and to possible small amounts of methyl or ethyl or vinyl acetylene and to propene. Ethyl acetylene can be shown to be present in no more than a trace as the 38 peak is 7.84 percent of the 54 peak; this is almost exactly the pattern for 1,3-butadiene. The ethyl acetylene pattern is almost twice this size.

The butadienes can now be resolved in the manner described for the butanes and the butenes by using the 54 base peak and the 39 peak.

Thus

39 peak $=0.9525 \mathrm{Bd}_{1,3}+0.3915 \mathrm{Bd}_{1,2}=1005.66$ divisions

54 peak $=1.00 \mathrm{Bd}_{1,3}+1.00 \mathrm{Bd}_{1,2}=1058.90$ divisions

\section{1,3 -Butadiene $=1053.65$ divisions \\ 1,2 -Butadiene $=5.25$ divisions.}

These values appear in columns 8 and 9 (table 3 ) at mass 54 . The contributions of the butadienes can now be computed and subtracted. The residuals are given in column 10 .

The residuals are particularly important in that they show errors in approximations as well as errors in readings and in computations. Positive residuals indicate too little estimated, whereas negative residuals indicate too much subtracted. In the present case the residuals are all small and within the limits of reading error. This indicates the correctness of the assumption that propene and the various acetylenes were absent.

The accuracy of the above assumptions can be estimated by considering the size of the residuals that would have been left had 1 percent of the various possible contaminants been present. These values would be: for propene, 18 divisions on 42 ; for carbon dioxide, 20 divisions on 44; for ethyl acetylene, 19 divisions on 54 ; for vinyl acetylene, 21 divisions on 52 ; and for propadiene, 11 divisions on 40 . In addition, each compound would contribute to the residuals on peaks of lower mass than those mentioned. The residuals on all peaks are weighed in the final calculations.

In order to calculate the mole percent of each constituent, the number of divisions of the various components must be divided by the sensitivity. This converts divisions to microns of pressure. The sum 
of all the partial pressures gives the total "computed" pressure of the sample. This pressure should be identical to the "read" pressure as given by the mercury manometer on the inlet measuring volume. The read and computed pressures, however, usually differ by a few tenths of a millimeter, due primarily to water vapor in the sample, which is adsorbed on and later desorbed from the dry glass walls of the inlet system. As water is almost always present and cannot be measured accurately, it is never advisable to compute the concentration of any component by difference. All percentages, therefore, are figured by the use of the "computed" microns as a measure of total pressure of the sample.

\section{REPRESENTATIVE ANALYSES}

The types of gas mixtures that can be analyzed with the mass spectrometer can best be illustrated by representative analyses made at the Bureau.

The results obtained from a series of butadiene samples are shown in table 4. Included in the table are the freezing point values for 1,3-butadiene as measured by F. D. Rossini.

TABLE 4.-Mass Spectrometer (mole percent)

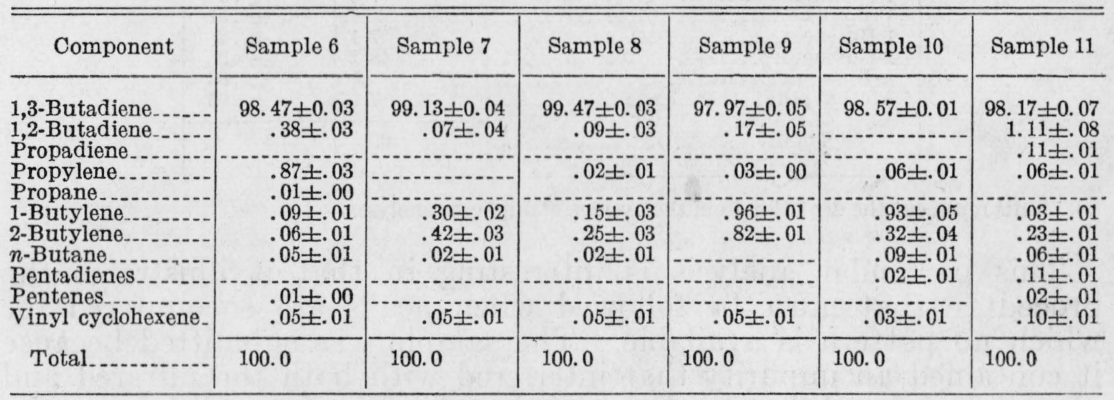

FREEZING POINT (MOLE PERCENT) b

\begin{tabular}{l|l|l|l|l|l|l}
\hline 1,3-Butadiene_-_-- & $98.56 \pm 0.08$ & $99.16 \pm 0.08$ & $99.40 \pm 0.08$ & $97.99 \pm 0.08$ & $98.22 \pm 0.08$ & $98.10 \pm 0.01$ \\
\hline
\end{tabular}

a Limits represent maximum deviation from average of 2 independent analyses.

b Limits of uncertainty estimated by F. D. Rossini.

The reproducibility of independent analyses is illustrated in table 5 .

TABLE 5.-Refined butadienes

\begin{tabular}{|c|c|c|c|c|}
\hline \multirow[b]{2}{*}{$\begin{array}{l}\text { Run number } \\
\text { Computed by. } \\
\text { Operator }\end{array}$} & \multicolumn{4}{|c|}{ Cylinder 11-20 } \\
\hline & $\begin{array}{l}1141 \mathrm{~A} \\
\text { DIT } \\
\text { LP }\end{array}$ & $\begin{array}{l}\text { 1141B } \\
\text { VHD } \\
\text { LP }\end{array}$ & $\begin{array}{l}1158 \\
\text { LE } \\
\text { VHD }\end{array}$ & $\begin{array}{l}1159 \\
\text { DIT } \\
\text { VHD }\end{array}$ \\
\hline 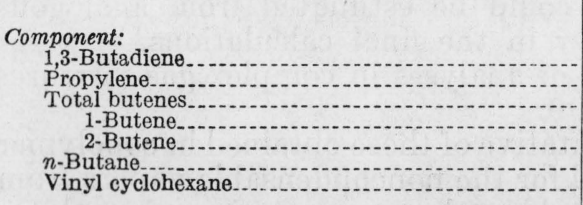 & $\begin{array}{r}\text { Mole } \\
\text { percent } \\
98.62 \\
.03 \\
1.32 \\
.41 \\
.91 \\
.02 \\
.02\end{array}$ & $\begin{array}{r}\text { Mole } \\
\text { percent } \\
98.63 \\
.03 \\
1.30 \\
.35 \\
.95 \\
.02 \\
.02\end{array}$ & $\begin{array}{r}\text { Mole } \\
\text { percent } \\
98.61 \\
.03 \\
1.33 \\
.49 \\
.84 \\
.02 \\
.02\end{array}$ & $\begin{array}{r}\text { Mole } \\
\text { percent } \\
98.63 \\
.02 \\
1.31 \\
.45 \\
.86 \\
.02 \\
.02\end{array}$ \\
\hline Total ....... & 100.0 & 100.0 & 100.0 & 100.0 \\
\hline
\end{tabular}


Runs $1141 \mathrm{~A}$ and $1141 \mathrm{~B}$ were made on the same day. Runs 1158 and 1159 were made 1 week later. The samples were withdrawn from a standard 1-quart ICC container nearly filled with liquid. The technic employed was to set the cylinder in an upright position and remove 0.4 milliliter of liquid from the bottom valve by means of a special liquid sampler, made from two small needle valves connected by a short piece of 2.0 millimeter capillary tubing. The entire quantity of liquid in the capillary was expanded into an evacuated glass cylinder, from which one or more vapor samples were withdrawn for analyses. Each analysis refers to a separate liquid sample computed on an entirely independent basis.

The reproducibility obtained in an impure sample of butadiene is illustrated in table 6 . The extent to which the deviations given are due to sampling and to the instrument is difficult to tell. Errors from both sources should increase with the impurity.

TABLE 6.-Crude butadiene

\begin{tabular}{|c|c|c|}
\hline Component & \multicolumn{2}{|c|}{ Mole percent } \\
\hline $\begin{array}{l}\text { 1,3-Butadiene-1, } \\
\text { 1,2-Butadiene- } \\
\text { Propylene } \\
\text { 2-Butene-Butene } \\
\text { n-Butane } \\
\text { Methyl ethyl ether }\end{array}$ & $\begin{array}{c}34.80 \\
1.8 \\
.02 \\
7.1 \\
48.2 \\
.10 \\
7.97\end{array}$ & $\begin{array}{l} \pm 0.07 \\
\pm .2 \\
\pm .01 \\
\pm .2 \\
\pm .3 \\
\pm .03 \\
\pm .05\end{array}$ \\
\hline Total & 100 & \\
\hline
\end{tabular}

- Limits represent the deviation from the average of duplicate analyses.

This particular analysis is interesting in that it illustrates the procedure that must be followed when peaks are encountered for which no pattern is available. The sample was submitted because it contained an impurity that interfered with both the infrared and ultraviolet absorbtion analyses of butadiene. In addition to the usual impurities the pattern showed a set of peaks with primary contributions at 60,45 , and 31 . These masses can only result from the fragmentation of $n$ - or isopropyl alcohol, acetic acid, methyl formate or methyl ethyl ether. Each of these compounds was obtained and its pattern determined; methyl ethyl ether alone agreed with the sample pattern.

In the event that the pattern for the possible contaminants could not have been obtained, the one actually present could have been identified and its concentration estimated with a reasonable degree of accuracy. The ratio of 61 and 46 isotope peaks to the 60 and 45 peaks showed only one oxygen atom to be present. This eliminated the formate and acetic acid. The two alcohols were improbable on the basis of boiling points. The sensitivity of methyl ethyl ether, the only remaining possibility, could be estimated from analogous compounds with very little error in the final calculations.

The reproducibility and range of analyses in complex gas mixtures are illustrated in tables 7, 8, and 9.

The analyses given are representative of those obtained in copolymer plants for recycled butadiene and for the noncondensable vapors from the styrene condenser, whereas table 9 is representative of products of combustion of certain types of oil flames. 
TABLE 7.-Recovered butadiene

\begin{tabular}{|c|c|}
\hline Component & Mole percent \\
\hline $\begin{array}{l}\text { 1,3-Butadiene } \\
\text { 1,2-Butadiene } \\
\text { Propadiene. } \\
\text { Propylene. }\end{array}$ & $\begin{array}{l}70.53 \mathrm{a} \pm 0.04 \\
4.61 \pm .13 \\
2.42 \pm .01 \\
5.70 \pm .10 \\
13.8 \pm .1\end{array}$ \\
\hline $\begin{array}{l}\text { 2-Butene } \\
\text { Pentadienes } \\
\text { Pentenes. } \\
\text { Ptyrene. }\end{array}$ & $\begin{array}{l}2.15 \pm .09 \\
.31 \pm .01 \\
.11 \pm .01 \\
.050 \pm .001 \\
.05 \pm .02\end{array}$ \\
\hline $\begin{array}{l}\text { Vinyl cyclohexene } \\
\text { Air } \\
\text { Carbon dioxide }\end{array}$ & $\begin{array}{l}.04 \pm .01 \\
.18 \pm .01 \\
.08 \pm .02\end{array}$ \\
\hline Total ... & 100 \\
\hline
\end{tabular}

Limits represent the deviation from the average of duplicate analyses.

TABLE 8.-Noncondensible gases from styrene condenser

\begin{tabular}{|c|c|}
\hline Component & Mole percent \\
\hline 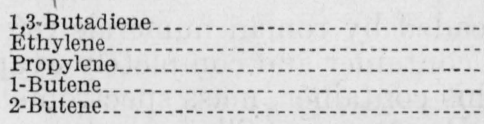 & $\begin{aligned} 22.96 & \pm 0.04 \\
.73 & \pm .08 \\
.08 & \pm .02 \\
2.99 & \pm .02 \\
5.71 & \pm .01\end{aligned}$ \\
\hline $\begin{array}{l}n \text {-Butane } \\
\text { Pentadienes } \\
\text { Pentenes_. } \\
\text { Styrene } \\
\text { Ethyl benzene... }\end{array}$ & $\begin{array}{l}.120 \pm .005 \\
.013 \pm .002 \\
.030 \pm .005 \\
.200 \pm .005 \\
.005 \pm .001\end{array}$ \\
\hline $\begin{array}{l}\text { Vinyl cyclohexene } \\
\text { Nitrogen } \\
\text { Oxygen } \\
\text { Argon } \\
\text { Carbon dioxide. }\end{array}$ & $\begin{array}{l}.140 \pm .005 \\
49.9 \pm .3 \\
11.49 \pm .02 \\
.560 \pm .001 \\
5.10 \pm .09\end{array}$ \\
\hline Total.. & 100 \\
\hline
\end{tabular}

a Limits represent the deviation from the average of duplicate analyses.

TABLE 9.-Oil flame fumes

\begin{tabular}{|c|c|}
\hline Component & Mole percent \\
\hline 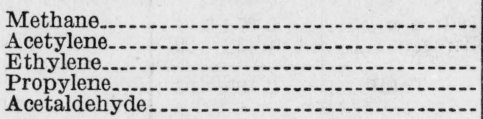 & $\begin{array}{l}0.48 \pm 0.05 \\
.05 \pm .01 \\
.45 \pm .04 \\
.06 \pm .01 \\
.18 \pm .02\end{array}$ \\
\hline $\begin{array}{l}\text { Butenes_..- } \\
\text { Benzene-ald } \\
\text { Toluene } \\
\text { Neon } \\
\text { Nitrogen }\end{array}$ & $\begin{aligned} & .02 \pm .01 \\
& .07 \pm .01 \\
& .010 \pm .005 \\
& .06 \pm .01 \\
& 77.7 \pm .1\end{aligned}$ \\
\hline $\begin{array}{l}\text { Carbon monoxide } \\
\text { Oxygen } \\
\text { Argon } \\
\text { Carbon dioxide }\end{array}$ & $\begin{array}{r}2.91 \pm .03 \\
6.53 \pm .06 \\
1.10 \pm .01 \\
10.38 \pm .02\end{array}$ \\
\hline Total. & 100 \\
\hline
\end{tabular}

- Limits represent the deviation from the average of duplicate analyses. 
Two magnet settings were required in taking the record for each mixture. A magnet current of 0.5 ampere was used to sweep the mass region from 12 to 90 and a current of 0.7 ampere for the region from 90 to 150 .

The reproducibility of the instrument, as well as that of the sampling technic described under table 5, is shown in table 10.

TABLE 10.-Hydrocarbon mixture

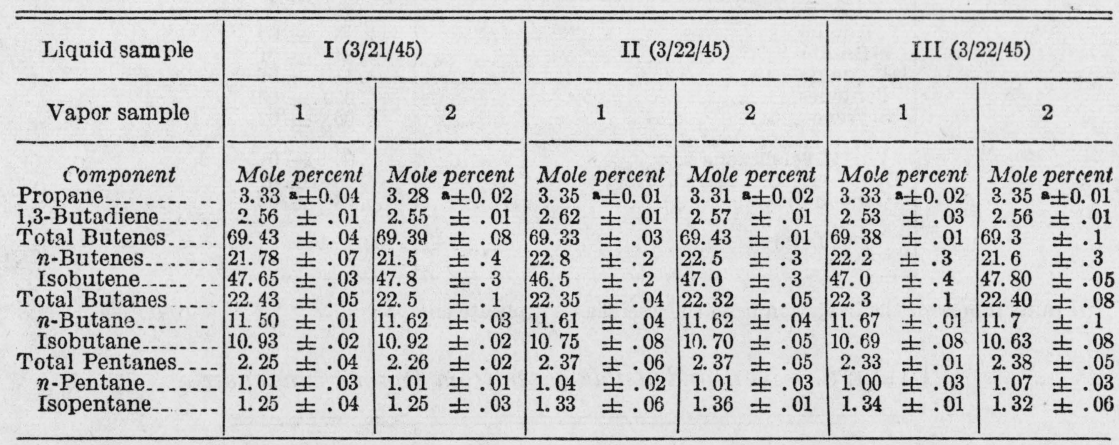

- Limits represent deviation from the average of 2 independent analyses of the same sample withdrawn from a vapor reservoir.

Each double column headed by roman numerals refers to a liquid sample removed from the container and completely evaporated into a vapor reservoir. From this container, mass spectrometer inlet reservoirs designated as A and B were twice filled simultaneously, as given by arabic numerals, 1 and 2 . The limits designated by " $a$ " are for the deviations from the average of the analyses of the vapor in $A$ and in $B$.

The deviations from the average in each single column represent the reproducibility of the instrument alone. The deviations between 1 and 2 represent reproducibility plus errors in sampling the vapor reservoir. The over-all spread under the roman numerals includes in addition the lack of uniformity in liquid sampling.

The impurities in tank helium from three Government owned plants are shown in table 11.

TABLE 11.-Helium from various helium plants

\begin{tabular}{|c|c|}
\hline \multicolumn{2}{|c|}{ OTIS, KANS. } \\
\hline Impurities & Mole percent \\
\hline $\begin{array}{l}\text { Hydrogen } \\
\text { Nitrogen }\end{array}$ & $\begin{array}{l}0.67 \pm 0.01 \\
1.43 \pm .02\end{array}$ \\
\hline Total_... & 2. $10 \pm .02$ \\
\hline \multicolumn{2}{|c|}{ EXELL, TEX. } \\
\hline $\begin{array}{l}\text { Hydrogen } \\
\text { Nitrogen.-... }\end{array}$ & $\begin{array}{l}0.36 \pm 0.02 \\
1.64 \pm .01\end{array}$ \\
\hline Total_... & $2.00 \pm .02$ \\
\hline \multicolumn{2}{|c|}{ NAVAJO, N. MEX. } \\
\hline $\begin{array}{l}\text { Hydrogen. } \\
\text { Nitrogen }\end{array}$ & $\begin{array}{l}0.70 \pm 0.03 \\
1.56 \pm .03\end{array}$ \\
\hline Total_.... & $2.26 \pm .03$ \\
\hline
\end{tabular}


The presence of hydrogen was completely unsuspected; it was later confirmed, however, by chemical tests. It was thought at first that the hydrogen might have come from the steel storage cylinders, but helium from glass cylinders contained the same percentage of impurities. An analysis of the natural gas showed a trace of hydrogen; apparently it was concentrated along with the helium in the purification process.

The composition of the naturallgas from which Texas helium is obtained is shown in table 12.

TABLE 12.-Natural gas

\begin{tabular}{|c|c|}
\hline Component & $\begin{array}{l}\text { Mole } \\
\text { percent }\end{array}$ \\
\hline Hydrogen & Trace \\
\hline Helium & $2.24 \pm \mathrm{b}^{0} 0.02$ \\
\hline Neon & $.12 \pm .01$ \\
\hline Nitrogen & $23.60 \pm .05$ \\
\hline Argon & $.18 \pm .01$ \\
\hline $\mathrm{CO}_{2} \ldots$ & $.52 \pm .05$ \\
\hline Oxygen & $.01 \pm .005$ \\
\hline Methane & $66.16 \pm .02$ \\
\hline $\begin{array}{l}\text { Ethane } \\
\text { Propane }\end{array}$ & $3.61 \pm .02$ \\
\hline 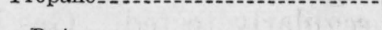 & 2. 10 \\
\hline$n$-Butane & $.85^{7} \pm 3.01$ \\
\hline Pentanes.1. & $.36 \pm .02$ \\
\hline $\begin{array}{l}\text { Hexanes_ } \\
\text { Heptanes and higher }\end{array}$ & $.07 \pm .02 \pm$ \\
\hline Total_ & 100 \\
\hline
\end{tabular}

- Maximum less than 0.05 mole percent.

b Limits represent deviation from average of 2 independent analyses.

It is interesting to note that the neon to nitrogen ratio is appreciably higher than that found in the atmosphere, whereas the argon to nitrogen ratio is slightly lower.

The analysis of a special gas test mixture is shown in table 13 . Four independent analyses were made by two computers. The sample was also analyzed by the Gas Chemistry Section of the Bureau.

TABLE 13.-Gas mixture analyses

\begin{tabular}{|c|c|c|c|c|c|c|}
\hline \multicolumn{6}{|c|}{ Mass spectrometer (mole percent) } & \multirow{2}{*}{$\begin{array}{c}\text { Gas section (mole } \\
\text { percent) }\end{array}$} \\
\hline Component & T574 & D582 & D588 & T589 & Average & \\
\hline $\begin{array}{l}\mathrm{O}_{2} \\
\mathrm{CO}_{2} \\
\mathrm{~N}_{2} \\
\text { Argon } \\
\text { Neon }\end{array}$ & $\begin{array}{r}0.44 \\
6.89 \\
82.06 \\
.99 \\
.14\end{array}$ & $\begin{array}{r}0.43 \\
6.94 \\
82.82 \\
.99 \\
.06\end{array}$ & $\begin{array}{r}0.44 \\
6.83 \\
82.97 \\
1.01 \\
.13\end{array}$ & $\begin{array}{r}0.42 \\
6.83 \\
82.46 \\
.98 \\
.12\end{array}$ & $\begin{array}{r}0.43 \pm 0.01 \\
6.87 \pm .07 \\
82.5 \pm .05 \\
.99 \pm .02 \\
.11 \pm .04\end{array}$ & $\begin{array}{r}0.37 \pm 0.04 \\
6.95 \pm .02 \\
82.99 \pm .02 \\
0\end{array}$ \\
\hline $\begin{array}{l}\mathrm{CO} \\
\mathrm{CH}_{4} \\
\mathrm{C}_{2} \mathrm{H}_{4} \\
\mathrm{C}_{3} \mathrm{H}_{6-2}\end{array}$ & $\begin{array}{l}9.24 \\
.08 \\
.06 \\
.02\end{array}$ & $\begin{array}{r}8.57 \\
.11 \\
.05 \\
.03\end{array}$ & $\begin{array}{l}8.31 \\
.10 \\
.07 \\
.03\end{array}$ & $\begin{array}{r}8.89 \\
.09 \\
.06 \\
.06\end{array}$ & $\begin{array}{l}8.8 \pm .5 \\
.10 \pm .02 \\
.06 \pm .01 \\
.04 \pm .02\end{array}$ & $\begin{array}{l}9.41 \pm 0.05 \\
.20 \pm .02 \\
\text { Unsaturated } \\
0.0 \pm 0.02\end{array}$ \\
\hline $\mathrm{H}_{2} \ldots$ & .08 & .08 & .12 & .10 & $.09 \pm .03$ & $.076 \pm .002$ \\
\hline
\end{tabular}


Two magnet settings were $^{\text {w }}$ used in taking the record, 0.15 ampere below mass 12 and 0.5 ampere above.

The separation of $\mathrm{N}_{2}$ and $\mathrm{CO}$ is not sharp. This is because the base peak for both gases is 28 . Separation must be made, therefore, by using the 14 and 12 peaks. For a 28 peak height of 100.00 the nitrogen 14 and carbon monoxide 12 peaks are 10.28 and 8.50, respectively; these adverse ratios result in a ten-fold magnification of the normal uncertainty.

\section{TYPE OF MATERIALS THAT CAN BE ANALYZED}

A sample to be analyzed successfully in the mass spectrometer should have an appreciable vapor pressure at room temperature. Materials having vapor pressures as low as $10^{-4}$ millimeter have been run in the instrument, but the peaks are too low for precise calculations. (In general, it is preferable that the vapor pressure exceed 1 millimeter for direct analyses.) A method will be described in succeeding articles by which the analyses of rubbers, plastics, and materials having no appreciable vapor pressure can be performed.

The chemical composition of the material to be analyzed is of little consequence. For the sake of longevity of the filament it is desirable to keep water vapor low although samples saturated with water vapor at atmospheric pressure are regularly tested. Gas mixtures containing small amounts of $\mathrm{PH}_{3}, \mathrm{H}_{2} \mathrm{~S}, \mathrm{SO}_{2}$, and chlorinated and fluorinated hydrocarbons offer no difficulty.

The most difficult materials to separate are the stereoisomers. The cracking patterns for cis- and trans-butene-2 are given in table 1 . The fragmentation ratios are very close, the greatest difference being for mass 29. The 58:29 mass ratios are sufficient to give a 1-percent separation in a mixture of pure butene-2. In a hydrocarbon mixture, however, a separation of better than 2 percent cannot be expected, even under favorable conditions. The cracking patterns for all the pentenes have not been worked out.

The range of masses that can be resolved in the instrument covers all masses up to 150 for the slit settings ordinarily used. The isotopes of mercury can be distinguished but resolution is not complete. In the analyses of hydrocarbons resolution above 150 is not essential, as the sensitivity can be determined from any lower peak of sufficient size, and the pattern can be taken from any series of carbon groups on the record. The analyses of heavy hydrocarbons is limited more by vapor pressure than by mass.

\section{ACCURACY OF ANALYSES}

A survey of some 1,700 determinations that have been run up to the present time leads to the conclusion that the precision of the mass spectrometer is high. Duplicate determinations in general check to within a few tenths to a few thousandths of 1 percent, the usual deviation being a few hundredths of 1 percent.

The absolute accuracy, in contrast, is not easy to determine. A large number of determinations have been compared with the freezing-point method. Agreements to within the limits of reproducibility have been obtained in every instance except one, in which case the container from which the sample was withdrawn was nearly 
empty. These results are not to be generalized, as freezing-point measurements can be made only on nearly pure materials.

A number of checks have been made against synthetic mixtures and with mixtures analyzed by chemical methods, and agreements to within a few tenths of 1 percent have been obtained. Such results, however, cannot be used to define the accuracy, as in no case was the composition known to be within the limits of deviation. It is obvious that the limits of accuracy should not be defined by occasional extreme cases of agreement or disagreement.

Errors in analysis enter from three different sources: (1) the instrument, (2) the sample, and (3) the computations.

The problem of obtaining a representative sample is far from simple. The principal source of instrumental error results from a time-totime variation in the sensitivity, or the cracking pattern or both. The effect of these variations can be largely overcome by checking the pattern and sensitivity for the most abundant constituents in the mixture being tested and then correcting the patterns and sensitivities of the other constituents proportionally. Thus, in the analysis of butadiene, the pattern error can be rendered negligible by running pure butadiene every day and correcting the patterns of all the other constituents therefrom. It should be pointed out that a daily check on the pattern is not imperative except in obtaining the precision reported in this paper.

Instrumental errors may also enter through fractionation in the gas-inlet leak. When capillary leaks are used, fractionation errors may be large; in the special leak used on the instrument this source of error is reduced to negligible proportions.

Errors in computation, may enter through the use of incorrect patterns and sensitivities for the various constituents in the sample and through an improper interpretation of the pattern for the mixture.

For the most part, instrumental errors are manifest by lack of reproducibility between duplicate analyses, whereas computational, errors are indicated by the magnitude of the residuals, such as those shown in the last column of table 3 .

In view of the number and nature of the various contributing factors involved, it is impossible to define the accuracy of a result obtained with the mass spectrometer by any given set of limits. In the analyses given in this report there is sufficient reason to believe that the absolute accuracy is very close to the limits of reproducibility. Analyses have been made, however, that contained mistakes in judgment in interpreting the mixture pattern, and in which incorrect calibrating patterns were used. In these instances the residuals were usually large.

In general, it can be stated that when the residuals are small the limits of accuracy are of the same order of magnitude as the limits of reproducibility, and when the residuals are large the limits of accuracy may be correspondingly large.

The authors are indebted to $\mathrm{H}$. W. Bond for preparing many of the hydrocarbons used as standards, to Dorothy Thompson and Laura Edmundson for making many of the computations shown, and to O. L. Parham for operating the mass spectrometer.

Washington, June 12, 1945.

$654385-45-3$ 